\title{
Aspergillosis Superinfection as a Cause of Death of Crizotinib-Induced Interstitial Lung Disease Successfully Treated with High-Dose Corticosteroid Therapy
}

\author{
Laura Deiana $^{a} \quad$ Salvatore Grisanti ${ }^{b}$ Vittorio Ferrari ${ }^{b} \quad$ Andrea Tironi $^{d}$ \\ Giulia Brugnoli $^{b} \quad$ Laura Ferrari $^{\mathrm{b}} \quad$ Giordano Bozzola $^{c} \quad$ Alfredo Berruti $^{\mathrm{b}}$ \\ ${ }^{a}$ Department of Medical Oncology, Centre Hospitalier, Montelimar, France; \\ ${ }^{b}$ Department of Medical and Surgical Specialties, Radiological Sciences and Public Health, \\ Medical Oncology, and ${ }^{\mathrm{C}}$ Pneumology Unit, Spedali Civili Hospital, and ${ }^{\mathrm{d}}$ Section of \\ Anatomic Pathology, Oncology and Experimental Immunology, Department of Molecular \\ and Translational Medicine, University of Brescia, Brescia, Italy
}

\section{Key Words}

Crizotinib · Non-small cell lung cancer · Acute interstitial lung disease

\begin{abstract}
Crizotinib is an efficacious and well-tolerated drug in the management of ALK-positive lung cancer. Crizotinib treatment, however, is rarely complicated by the occurrence of acute interstitial lung disease (ILD) that is often fatal. There is no treatment for this serious adverse event. We report a female non-small cell lung cancer patient who developed ILD after a few days of crizotinib therapy. She showed a significant improvement after a high dose of pulse corticosteroid therapy, both radiologically and clinically. Unfortunately, the patient subsequently developed an aspergillosis superinfection leading to death. Our experience suggests that high-dose steroid therapy may be efficacious in the management of a severe complication of crizotinib therapy. However, potent antifungal therapy should be considered to prevent the risk of severe aspergillosis.

(c) 2015 S. Karger AG, Basel
\end{abstract}

KARGER 125/s $\begin{aligned} & \text { Laura Deiana } \\ & \text { Department of Medical Oncology, Centre Hospitalier } \\ & \text { Quartier de Beausseret BP 249 } \\ & \text { F-26216 Montelimar (France) } \\ & \text { E-Mail lauradeiana@gmail.com }\end{aligned}$


Deiana et al:: Aspergillosis Superinfection as a Cause of Death of Crizotinib-Induced Interstitial Lung Disease Successfully Treated with High-Dose Corticosteroid Therapy

\section{Case Presentation}

Crizotinib is a tyrosine kinase inhibitor of ALK, c-MET and ROS1 currently approved as a second-line treatment for $A L K$-rearranged lung cancer in advanced non-small cell lung cancer [1].

Despite its manageable toxic profile, crizotinib administration is rarely complicated by the occurrence of interstitial lung disease (ILD) that is often life threatening and for which there is no proven effective therapy.

A 55-year-old female nonsmoker was diagnosed with lung adenocarcinoma with multiple metastases on pleura, chest wall, liver and brain. The patient received whole-brain radiation therapy followed by 6 chemotherapy cycles with pemetrexed and cisplatin. A CT scan revealed disease stabilization after 3 cycles and disease progression on liver after 6 cycles. Second-line chemotherapy with docetaxel was interrupted after 3 cycles due to inefficacy. Since fluorescence in situ hybridization analysis demonstrated the presence of an ALK rearrangement, the patient received oral crizotinib $250 \mathrm{mg}$ twice daily. After a 10-day treatment, she developed severe dyspnea requiring hospitalization. On admission, no fever and no demonstrable infection was documented. Arterial blood gas determination showed $\mathrm{PaO} 260$ $\mathrm{mm} \mathrm{Hg}$, PaCo2 $36 \mathrm{~mm} \mathrm{Hg}$ and $\mathrm{Ph}$ 7.45. Hemochrome and routine chemistry were within normality. The high-resolution CT scan revealed the appearance of diffuse extensive bilateral ground-glass opacities involving both lungs (fig. 1a, b). Bronchoscopy with bronchoalveolar lavage was performed, and the bronchoalveolar lavage fluid was negative for infective etiology such as bacteria, fungal elements and acid-fast bacilli. Crizotinib treatment was discontinued, and a high-dose pulse corticosteroid therapy with desametasone $12 \mathrm{mg}$ every $6 \mathrm{~h}$ was prescribed in association with an empirical antibiotic treatment with meropenem, ciprofloxacin, trimethoprim-sulfamethoxazole and fluconazole. Oxygen via mask at a high flow rate of $10 \mathrm{l} / \mathrm{min}$ was introduced. The patient obtained an immediate benefit with improvement of arterial blood gas parameters (PaO2 $75 \mathrm{~mm} \mathrm{Hg}$ without oxygen), and a CT scan after 2 weeks showed a partial remission of the disease (fig. 1c). After 3 days, however, a sudden worsening of the dyspnea and the clinical status was documented, leading to patient death 10 days later. Histological evaluation of autopsy lung tissue showed areas of interstitial organizing fibrosis, carcinomatous lymphangitis and, more importantly, fungal hyphae consistent with aspergillus spp. invading alveoli and vessels (fig. 2) with areas of ischemic necrosis (invasive aspergillosis). This diffuse mycosis was the presumed cause of the rapid patient deterioration and death.

\section{Discussion}

Crizotinib is the inhibitor of combined ALK-EML4 c-Met and ROS1 [1, 2]. The inhibition of tumor growth is a key of drug-induced toxicity. From the ALK-EML4 results fusion protein that actives many different pathways including the Ras/Raf/MEK/ERK1/2 cell proliferation module, the JAK/STAT (janus-activated kinase/signal transducer and activator of transcription) cell survival pathway, the PI3K (phosphatidylinositol 3-kinase)/Akt (PKB) pathway and the PLC (phospholipase C) pathway. The Akt activated catalyzes the phosphorylation and activation of mTOR (mammalian target of rapamycin) [3]. Akt/mTOR can be involved in immunosuppressive processes, biomolecular pathways and signals that are crucial in the development of lung injury [4].

International guidelines recommend the use of high-dose pulse corticosteroid therapy in the management of ILD $[5,6]$. This case report suggests that this treatment, promptly 
Deiana et al: : Aspergillosis Superinfection as a Cause of Death of Crizotinib-Induced Interstitial Lung Disease Successfully Treated with High-Dose Corticosteroid Therapy

administered, was also efficacious in ILD induced by crizotinib, probably by interrupting the inflammatory cascade before the occurrence of irreversible tissue injury. However, glucocorticoids have potent immunosupressive effects that might have been even potentiated by previous crizotinib treatment that inhibits the mTOR pathway [4].

Immunosuppression favored the occurrence of fatal invasive aspergillosis. We believe that a more effective antifungal therapy than fluconazole, such as liposomal amphotericyn B, voriconazole or caspofungin, would have been more appropriate in the management of our patient [7].

In conclusion, ILD is a severe complication of crizotinib therapy that can be successfully managed by the early administration of high-dose pulse corticosteroid therapy. However, aggressive antifungal therapy should be concomitantly administered in order to prevent aspergillosis superinfection.

\section{References}

$\checkmark 1$ Shaw AT, Ou S-HI, Bang Y-J, et al: Crizotinib in ROS1-rearranged non-small-cell lung cancer. N Engl J Med 2014;371:1963-1971.

$>2$ Shaw AT, Kim D-W, Nakagawa K, Seto T, Crinó L, et al: Crizotinib versus chemotherapy in advanced ALKpositive lung cancer. N Engl J Med 2013;368:2385-2394.

-3 Roskoski R Jr: Anaplastic lymphoma kinase (ALK): structure, oncogenic activation, and pharmacological inhibition. Pharmacol Res 2013;68:68-94.

4 Aparicio G, Calvo MB, Medina V, et al: Comprehensive lung injury pathology induced by mTOR inhibitors. Clin Transl Oncol 2009;11:499-510.

5 Mukhopadhyay S, Parambil JG: Acute interstitial pneumonia (AIP): relationship to Hamman-Rich syndrome, diffuse alveolar damage (DAD), and acute respiratory distress syndrome (ARDS). Semin Respir Crit Care Med 2012;33:476-485

6 Rhen T, Cidlowski JA: Antiinflammatory action of glucocorticoids - new mechanisms for old drugs. N Engl J Med 2005;353:1711-1723.

7 Maschmeyer G, Beinert T, Buchheidt D, et al: Review Diagnosis and antimicrobial therapy of lung infiltrates in febrile neutropenic patients: guidelines of the infectious diseases working party of the German Society of Haematology and Oncology. Eur J Cancer 2009;45:2462-2472. 


\section{Case Reports in Oncology}

\begin{tabular}{l|l}
\hline \multicolumn{2}{l|}{ Case Rep Oncol 2015;8:169-173 } \\
\hline DOI: $10.1159 / 000381209$ & $\begin{array}{l}\text { C } 2015 \text { S. Karger AG, Basel } \\
\text { www.karger.com/cro }\end{array}$ \\
\hline
\end{tabular}

Deiana et al.: Aspergillosis Superinfection as a Cause of Death of Crizotinib-Induced Interstitial Lung Disease Successfully Treated with High-Dose Corticosteroid Therapy
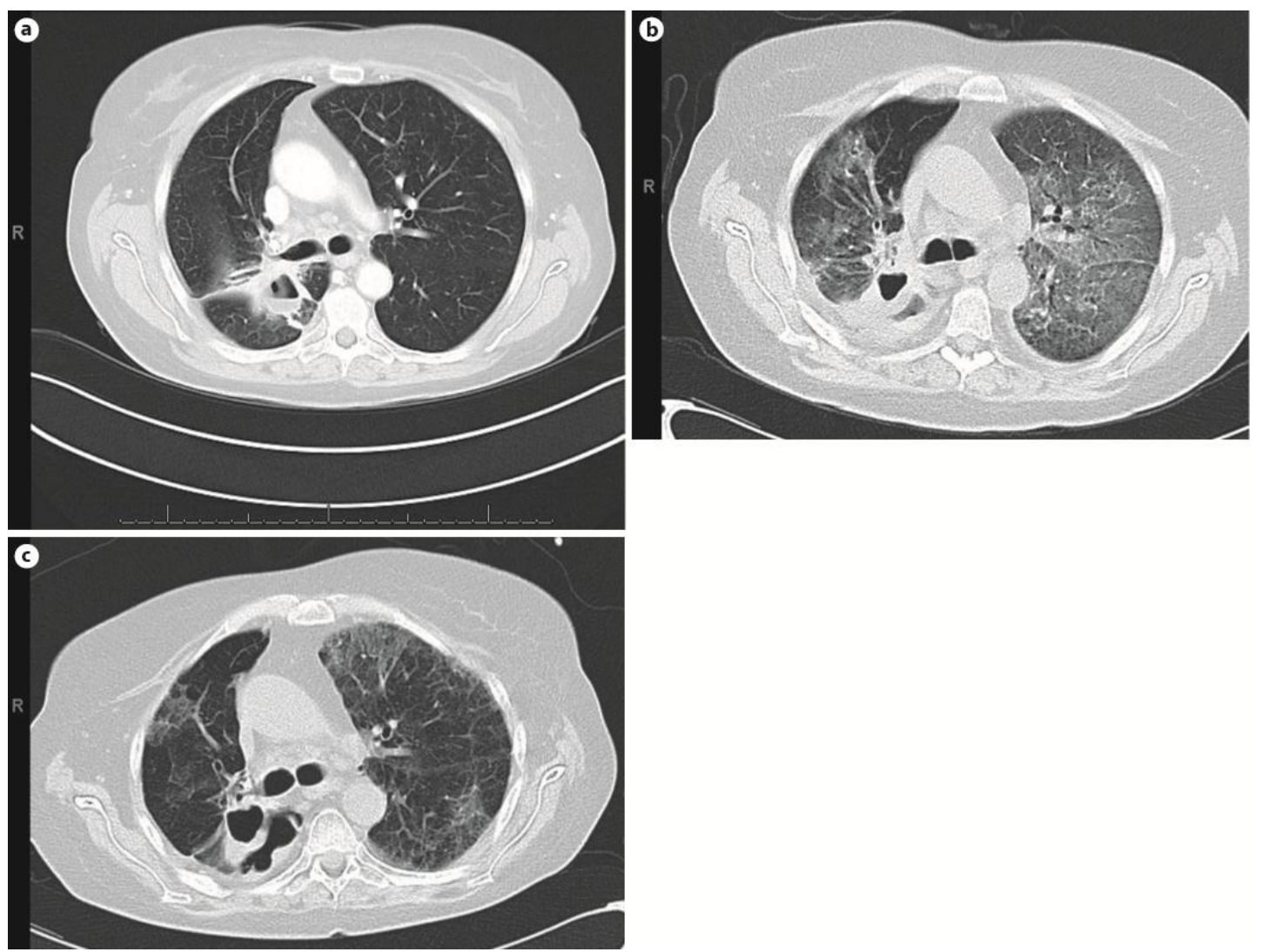

Fig. 1. a The tumor lesion before crizotinib administration was mainly necrotic with air-fluid level and had a diameter of about $41 \mathrm{~mm}$, ilo-perihilar right. b After 10 days of crizotinib administration, a CT scan of the chest showed extensive bilateral ground-glass opacities throughout both lungs and a further increase in the solid lesion (excavated), which measured about $60 \mathrm{~mm}$. c After treatment with corticosteroid, a reduction of the ground-glass component occurred bilaterally, while the lesion in the right lower lobe appeared essentially unchanged in morphology and size. 
Deiana et al.: Aspergillosis Superinfection as a Cause of Death of Crizotinib-Induced Interstitial Lung Disease Successfully Treated with High-Dose Corticosteroid Therapy

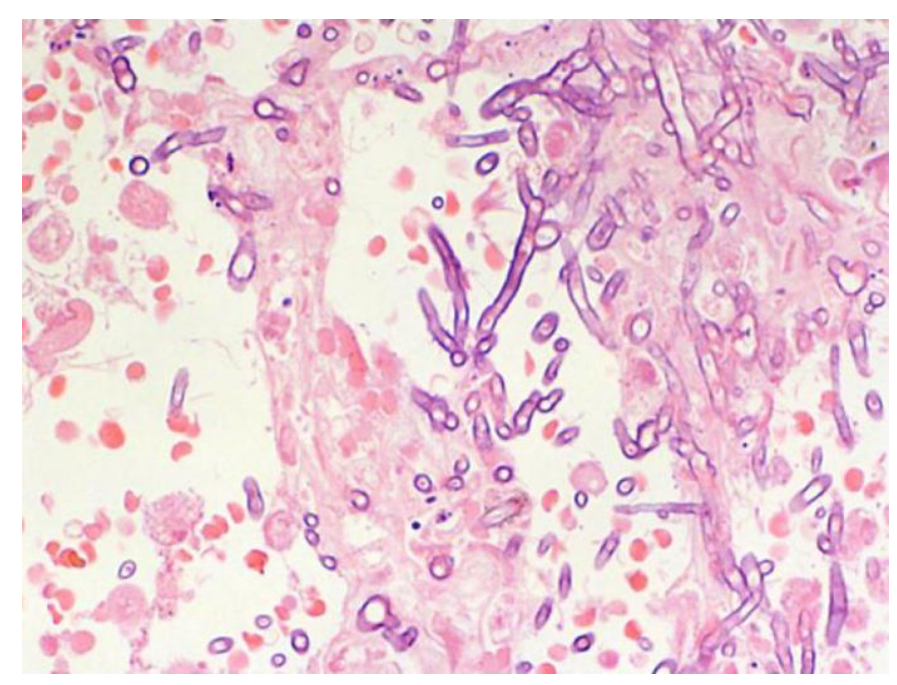

Fig. 2. Diffuse invasive aspergillosis observed in autopsy lung tissue $(\mathrm{HE} \times 400)$. 